\title{
Contemporary Locoregional Recurrence Rates in Young Patients With Early-Stage Breast Cancer
}

Kim C. Aalders, Emily L. Postma, Luc J. Strobbe, Margriet van der Heiden-van der Loo, Gabe S. Sonke, Liesbeth J. Boersma, Paul J. van Diest, Sabine Siesling, and Thijs van Dalen

See accompanying editorial on page 2079

Kim C. Aalders, Emily L. Postma, and Thijs van Dalen, Diakonessenhuis; Margriet van der Heiden-van der Loo and Sabine Siesling, Netherlands Comprehensive Cancer Organization; Paul J. van Diest, University Medical Center Utrecht, Utrecht; Luc J. Strobbe, Canisius Wilhelmina Hospital, Nijmegen; Gabe S. Sonke, Netherlands Cancer Institute, Amsterdam; Liesbeth J. Boersma, University Hospital Maastricht, Maastricht; and Sabine Siesling, University of Twente, Enschede, the Netherlands.

Published online ahead of print at www.jco.org on March 14, 2016.

Terms in blue are defined in the glossary, found at the end of this article and online at www.jco.org.

Authors' disclosures of potential conflicts of interest are found in the article online at www.jco.org. Author contributions are found at the end of this article.

Corresponding author: Kim C. Aalders, MD, Diakonessenhuis, Bosboomstraat 1 3582 KE Utrecht, the Netherlands; e-mail: kaalders@diakhuis.nl.

C 2016 by American Society of Clinical Oncology

0732-183X/16/3418w-2107w/\$20.00

DOI: 10.1200/JCO.2015.64.3536

\section{$\begin{array}{llllllll}\text { A } & \text { B } & \text { S } & \text { T } & \text { R } & \text { A } & \text { C } & \text { T }\end{array}$}

\section{Purpose}

The aim of this study was to evaluate contemporary rates of local recurrence (LR) and regional recurrence $(R R)$ in young patients with breast cancer in relation to tumor biology as expressed by biomarker subtypes.

\section{Patients and Methods}

Women $<35$ years of age who underwent surgery for primary unilateral invasive breast cancer between 2003 and 2008 were selected from the Netherlands Cancer Registry. Patients were categorized according to biomarker subtypes on the basis of hormone receptor (HR) and human epidermal growth factor receptor 2 (HER2) status. The 5-year risks of developing LR and regional lymph node recurrence were estimated by using Kaplan-Meier statistics.

\section{Results}

A total of 1,000 patients were identified, of whom 59\% had a known subtype: $39 \%$ HR-positive/HER2negative; 17\% HR-positive/HER2-positive; 10\% HR-negative/HER2-positive; and 34\% HR-negative/HER2negative (triple negative). Overall 5-year LR and RR rates were 3.5\% and 3.7\%, respectively. A decreasing trend for both rates was observed over time and was accompanied by a significant decrease in the risk of distant metastases (DM). LR occurred in 4.2\%, RR in 6.1\%, and DM in 17.8\% of patients in 2003, and in $3.2 \%, 4.4 \%$, and $10.0 \%$, respectively, in 2008 . LR and RR rates varied with biomarker subtype. These differences were borderline significant when analyzed for the entire study period $(P=.056$ and $P=.014$, respectively) and leveled off after the introduction of trastuzumab after $2005(P=.24$ and $P=.42$, respectively). Patients with lymph node metastases at the time of diagnosis had an increased risk of RR. The type of surgery performed-breast-conserving or mastectomy—did not influence rates of LR and RR.

\section{Conclusion}

Overall, the rates of $L R$ and RR in young patients with early-stage breast cancer were relatively low and varied by biomarker subtype.

J Clin Oncol 34:2107-2114. (C) 2016 by American Society of Clinical Oncology

\section{INTRODUCTION}

Of all patients with breast cancer in the Netherlands, $2 \%$ are younger than 35 years of age at the time of diagnosis. ${ }^{1}$ Historically, young patients with breast cancer have had a poorer prognosis and a higher risk of locoregional recurrence (LRR). ${ }^{2-4}$ Younger patients with breast cancer seem to possess a more aggressive tumor biology compared with older women with breast cancer. This is reflected by the high proliferation and poor differentiation rates and by a higher frequency of hormone receptor (HR)-negative tumors. ${ }^{5}$ In addition, unfavorable gene expression profiles are more frequently observed as well as the occurrence of pathogenic germ-line mutations, such as $B R C A 1$ and BRCA2. ${ }^{6-9}$

Previous studies observed significantly higher rates of local recurrence (LR) in young patients who underwent breast-conserving surgery (BCS) compared with older patients and those who underwent a mastectomy, even though overall survival did not differ. ${ }^{10-14}$ Young age has been considered a justification for more aggressive surgical approaches to prevent LRs. ${ }^{10-14}$ Until 2005, this was reflected in the Dutch Breast Cancer Guideline, which stated that young age ( $\leq 40$ years) was an independent risk factor for LR after breast-conserving therapy. ${ }^{15}$ During the 
last two decades, the occurrence of distant metastases(DM) has decreased $^{16,17}$ and the survival of patients with breast cancer has greatly improved. At the same time, LRR rates have also decreased. ${ }^{18}$ Developments in systemic treatment, such as the introduction of trastuzumab, ${ }^{19,20}$ are considered to be the most important factor in both of these manifestations. ${ }^{10}$ The evolution of radiotherapy techniques and regimes has also contributed to the decreasing rates of LR. Furthermore, the introduction of advanced computed tomography-based treatment planning has increased the precision of dose delivery considerably, leading to reduced toxicity. $^{21}$

The diminishing LRR rates in the overall population of patients with breast cancer and the acknowledgment of tumor biology and biomarker subtypes in relation to age has raised the question of whether the historically high risk of LRR has decreased in young women during a time in which systemic treatment has evolved, in particular, for the aggressive tumor types that frequently occur in young women. The aim of this study was to evaluate contemporary rates of LR and regional recurrence (RR) in young patients with breast cancer and the association with tumor biology as expressed by tumor biomarker subtypes.

\section{PATIENTS AND METHODS}

Patient data were selected from the population-based Netherlands Cancer Registry (NCR). The NCR contains data on patient and tumor characteristics and information regarding the applied treatment. On the basis of a notification from the Pathological Anatomy National Automated Archive, trained NCR personnel register the information directly from patients' medical records from all hospitals. The use of this data was approved by the NCR Committee of Privacy.

Patients selected were women between the ages of 20 and 35 years who were diagnosed with primary invasive, nonmetastatic breast cancer and underwent surgery between 2003 and 2008. Patients excluded from the study were those with a previous breast cancer diagnosis, with synchronous contralateral breast cancer, who received neoadjuvant treatment $(n=150)$, who lived or were treated outside the Netherlands, and those with incomplete follow-up data (eg, no information or missing event date). Only 43 hospitals (47\%) provided follow-up data during 2007 and 2008 compared with all hospitals ( $\mathrm{n}=92$ ) from 2003 to 2006.

Patient and tumor characteristics were collected from all patients. Tumor size and metastatic lymph node involvement were recorded according to the TNM system of the Union for International Cancer Control and the American Joint Committee on Cancer that was applicable at the time of diagnosis. ${ }^{22}$ Estrogen receptor and progesterone receptor status were commonly available throughout the study period albeit fully available only from 2005. Standard assessment of human epidermal growth factor receptor 2 (HER2) status was implemented in the Netherlands in mid-2005. ${ }^{19}$ Biomarker subtypes were defined on the basis of HR and HER2 status and were categorized as HR-positive/HER2-negative, HRpositive/HER2-positive, HR-negative/HER2-positive, and HR-negative/ HER2-negative (triple negative [TN]).

Information was obtained regarding the type of surgery patients underwent-BCS or mastectomy_-as defined by the last surgical procedure for the primary tumor. Positive tumor margins consisted of microscopic margin involvement after final surgery. Information regarding administered radiotherapy (yes or no), chemotherapy (yes or no), hormonal treatment (yes or no) and immunotherapy (yes or no) was obtained from the NCR, although detailed data on specific treatment regimens were not available. Five-year follow-up data for LR, RR, and DM, whichever occurred first, were collected for all patients in retrospect by NCR
Table 1. Clinicopathologic Characteristics of Surgically Treated Patients With Primary Breast Cancer Age $<35$ Years Diagnosed Between January 1, 2003 and December 31, $2008(n=1,000)$

\begin{tabular}{|c|c|}
\hline Characteristic & No. of Patients (\%) \\
\hline \multicolumn{2}{|l|}{ Tumor histologic type* } \\
\hline Ductal & $897(90)$ \\
\hline Lobular & $25(3)$ \\
\hline Ductal and lobular & $27(3)$ \\
\hline Other* & $51(5)$ \\
\hline \multicolumn{2}{|l|}{ pT } \\
\hline $1 \mathrm{~A}$ & $36(4)$ \\
\hline 1B & $87(9)$ \\
\hline $1 \mathrm{C}$ & $379(38)$ \\
\hline 2 & $429(43)$ \\
\hline 3 & 47 (5) \\
\hline 4 & $5(1)$ \\
\hline $\mathrm{x}$ & $17(2)$ \\
\hline \multicolumn{2}{|l|}{$\mathrm{pN}$} \\
\hline pNO & $524(52)$ \\
\hline $\mathrm{pN} 1$ & $311(31)$ \\
\hline $\mathrm{pN}>1$ & $162(16)$ \\
\hline Unknown & $3(0)$ \\
\hline \multicolumn{2}{|l|}{ Grade } \\
\hline Well differentiated & $55(6)$ \\
\hline Moderately differentiated & $252(25)$ \\
\hline Poorly differentiated & $627(63)$ \\
\hline Unknown & $66(7)$ \\
\hline \multicolumn{2}{|l|}{ Multifocality } \\
\hline Yes & $158(16)$ \\
\hline No & $667(67)$ \\
\hline Unknown & $175(18)$ \\
\hline \multicolumn{2}{|l|}{ HR status } \\
\hline Positive & 489 (49) \\
\hline Negative & $374(37)$ \\
\hline Unknownt & $137(14)$ \\
\hline \multicolumn{2}{|l|}{ Biomarker subtype } \\
\hline HR-positive/HER2-negative & $230(23)$ \\
\hline HR-positive/HER2-positive & $98(10)$ \\
\hline HR-negative/HER2-positive & $59(6)$ \\
\hline TN & $202(20)$ \\
\hline Unknownt & $411(41)$ \\
\hline \multicolumn{2}{|l|}{ Final surgery } \\
\hline Breast conserving & $449(45)$ \\
\hline Mastectomy & $551(55)$ \\
\hline \multicolumn{2}{|l|}{ Positive tumor margins } \\
\hline Yes & $36(4)$ \\
\hline No & 939 (94) \\
\hline Unknown & 25 (3) \\
\hline \multicolumn{2}{|l|}{ ALND } \\
\hline Yes & $574(57)$ \\
\hline No & $426(43)$ \\
\hline \multicolumn{2}{|l|}{ Radiotherapy } \\
\hline Yes & $629(63)$ \\
\hline No & 371 (37) \\
\hline \multicolumn{2}{|l|}{ Chemotherapy } \\
\hline Yes & $933(93)$ \\
\hline No & $67(7)$ \\
\hline \multicolumn{2}{|l|}{ Hormone therapy } \\
\hline Yes & $480(48)$ \\
\hline No & $520(52)$ \\
\hline \multicolumn{2}{|l|}{ HER2 and trastuzumab } \\
\hline HER2-negative, no trastuzumab & $452(45)$ \\
\hline HER2-positive, no trastuzumab & $35(4)$ \\
\hline HER2-positive, trastuzumab & $123(12)$ \\
\hline Unknown & 390 (39) \\
\hline
\end{tabular}

NOTE. Percentages may not add up to $100 \%$ as a result of rounding. Abbreviations: ALND, axillary lymph node dissection; HER2, human epidermal growth factor receptor 2; HR, hormone receptor; $\mathrm{pN}$, pathological nodal status: pT, pathologic tumor size; TN, triple negative.

*Tumor histologic type other (eg, mucinous, medullary, metaplastic carcinoma). tUnknown biomarker subtype category mainly reflects the earlier years when HER2 status was not determined. 
personnel. For all patients, vital status was ascertained through linkage with the municipal registry through to December 31, 2013.

\section{Definitions of End Points}

Follow-up commenced at the date of final surgery and ended with any type of recurrence (event), death (censored), or the date of last follow-up (censored). LR was defined as the occurrence of breast cancer or ductal carcinoma in situ in the ipsilateral breast or in the skin or subcutaneous tissue of the ipsilateral chest wall. RR consisted of breast cancer recurrence in the ipsilateral regional lymph nodes (eg, axillary, infra- or supraclavicular or internal mammary nodes). DMs were used as end point to compare the previously reported downward trend in the occurrence of DM with the LRR end points.

\section{Statistical Analyses}

The distribution of clinicopathologic and treatment factors in the population of young patients with breast cancer was calculated and compared for the various biomarker subtypes by using $\chi^{2}$ tests. Subsequently, tumor characteristics in young patients were assessed over time. Time trends of different treatment modalities were evaluated by linear regression analyses.

Kaplan-Meier estimates were used to calculate univariate 5-year rates for LR and RR in the group of young patients with breast cancer. The trends of LR and RR and DM over time were evaluated by using linear regression analyses. DMs were included in this analysis to evaluate whether a similar trend could be observed between the occurrence of locoregional and distant breast cancer relapse over time. Subsequently, LR and RR rates were assessed according to biomarker subtypes for the entire study period and for the period that trastuzumab was reimbursed by insurers and routinely administered to patients (2005 to 2008). Within these groups, we assessed the association between the type of surgery and lymph node involvement with rates of LR and RR. Because the numbers of both LR and RR were low, reliable multivariable Cox proportional hazards regression analyses were not feasible. Therefore, all rates represent Kaplan-Meier estimates. The differences between groups were assessed by using log-rank tests.

STATA software version 13.1 (STATA, College Station, TX; Computing Resource Center, Santa Monica, CA) was used for all analyses. All statistical tests were two-sided, and $P<.05$ was considered statistically significant.

\section{RESULTS}

During the study period, 1,000 women with breast cancer, age $<35$ years at the time of diagnosis, underwent surgery for primary breast cancer, constituting $2 \%$ of the total population of patients with breast cancer who underwent surgery in that period in the Netherlands $(\mathrm{n}=52,310)$. The mean age of the group of young patients with breast cancer was 31 years (standard deviation \pm 2.83 years). The youngest patient was 20 years old. Tumor and treatment characteristics of the group of young patients are presented in Table 1. Between 2003 and 2008, the distribution of most tumor characteristics did not vary significantly as tumor grade, HR status, and lymph node involvement remained stable (Appendix Table A1, online only).

There was a significant proportional shift of tumor size during the study period $(P=.004)$ : the proportion of T1c tumors increased, whereas the proportion of T2 tumors decreased ( $P \leq .001$ using linear regression analyses). Overall, $95 \%$ of patients had early-stage breast cancer at pathology (stage I and II). The distribution of patients who underwent BCS remained stable over time. Axillary lymph node dissection was performed less often during the study period (from $69 \%$ in 2003 to $46 \%$ in 2008 ; $P<.001)$. The proportion of patients receiving chemotherapy and hormonal therapy did not increase significantly over time (Fig 1). The proportion of patients receiving immunotherapy (trastuzumab) increased steeply after 2004 with the introduction of standard trastuzumab treatment in HER2-positive patients in $2005(P<.001)$ and has been stable from $2006(P=.346)$.

Distributions of tumor characteristics by biomarker subtypes in the young age group are presented in Table 2. The unknown biomarker subtype category reflects the earlier years when HER2 status was not routinely determined; $96 \%$ of the patients in this

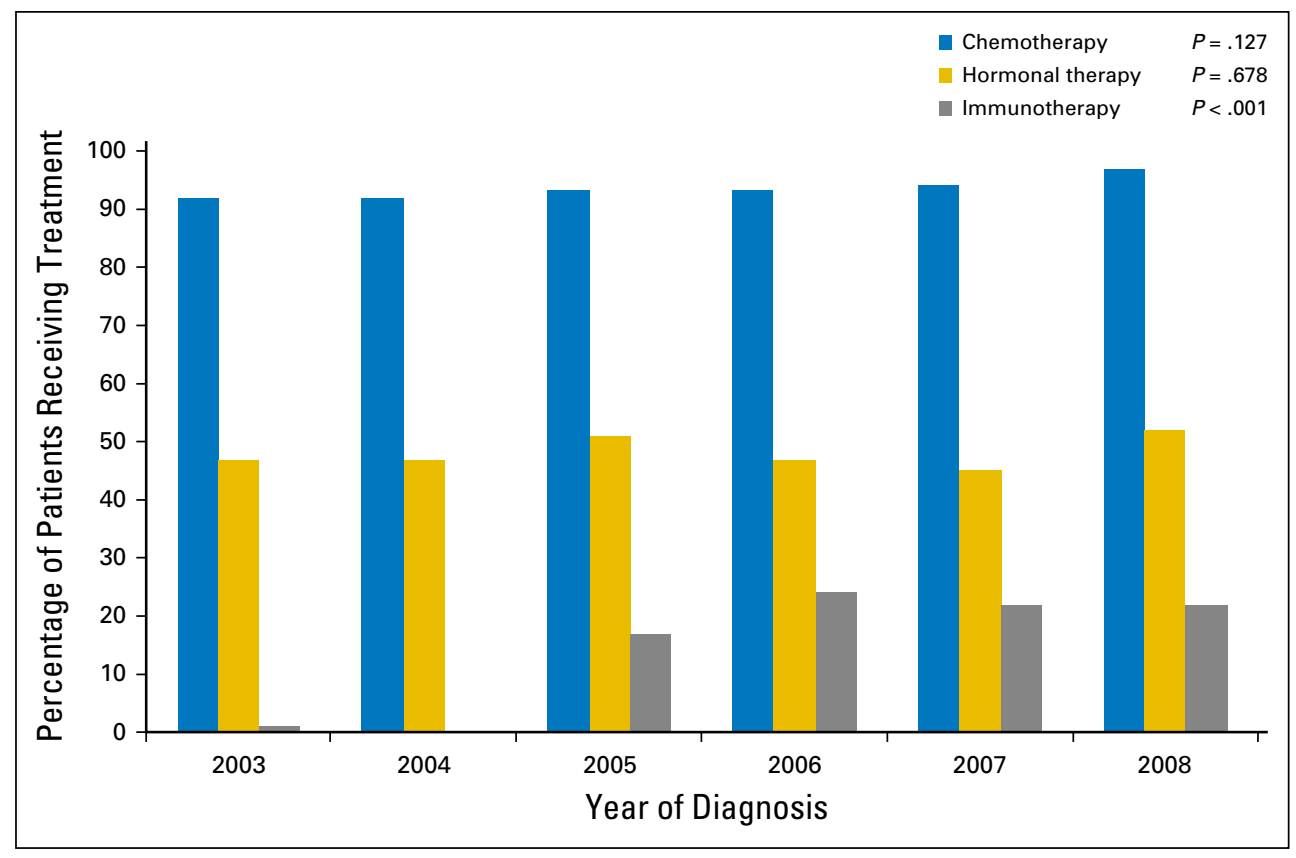

Fig 1. Time trends of systemic treatment modalities applied to 1,000 patients with breast cancer age $<35$ years during the study period of 2003 to 2008 . $P$ values for time trends of different treatment modalities were evaluated by linear regression analyses. Immunotherapy constitutes treatment with trastuzumab. 


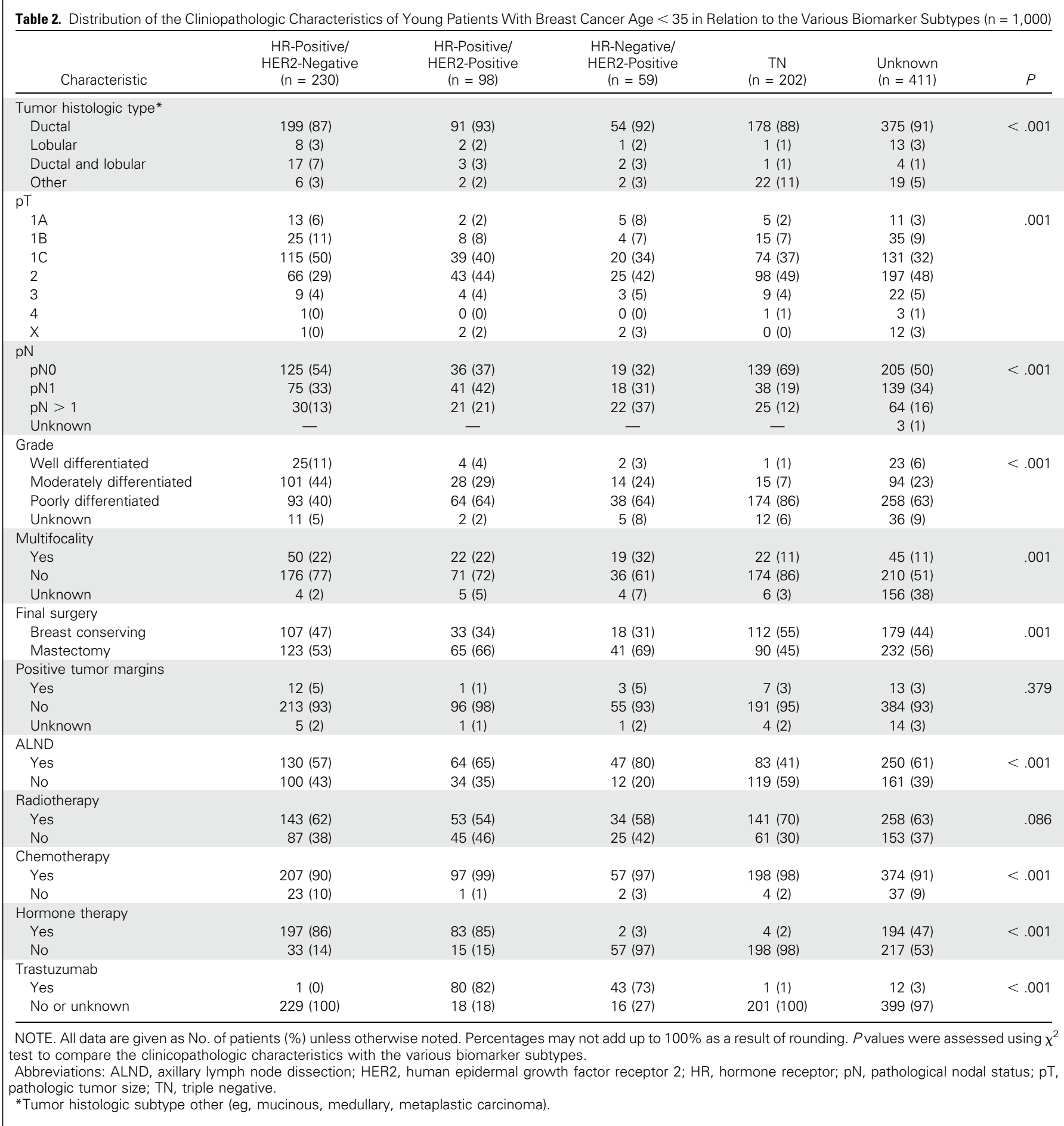

unknown category were treated between 2003 and 2005. HRpositive/HER2-negative tumors were present in $23 \%$ of patients and were generally smaller and of a lower malignancy grade compared with other subtypes $(P<.001)$. Patients with HER2negative tumors presented less often with lymph node metastases than did patients with HER2-positive breast cancer. Mastectomy was performed more frequently in patients with HER2-positive tumors compared with patients with HER2-negative tumors
(68\% $v 49 \%$; $P<.001$ ). The proportion of patients receiving chemotherapy did not vary significantly between the different subtypes.

The overall 5-year rates for development of local and regional breast cancer recurrence were $3.5 \%$ and $3.7 \%$, respectively (Table 3), and both rates showed a decreasing trend over time, although this was not significant. During the same period, the risk of DM decreased significantly in the entire cohort $(P=.040)$. The 


\begin{tabular}{|c|c|c|c|c|}
\hline Year & $\begin{array}{l}\text { No. of } \\
\text { Patients }\end{array}$ & $\begin{array}{c}\text { Local } \\
\text { Recurrence, } \\
\text { No.(\%)* }\end{array}$ & $\begin{array}{c}\text { Regional } \\
\text { Recurrence, } \\
\text { No.(\%)† }\end{array}$ & $\begin{array}{c}\text { Distant } \\
\text { Metastases, } \\
\text { No.(\%)† }\end{array}$ \\
\hline Overall & 1,000 & 31 (3.5) & $33(3.7)$ & 131 (13.9) \\
\hline 2003 & 213 & $8(4.2)$ & $11(6.1)$ & 36 (17.8) \\
\hline 2004 & 212 & $10(5.6)$ & $10(5.1)$ & 38 (19.2) \\
\hline 2005 & 182 & $3(2.0)$ & $5(3.1)$ & 25 (14.6) \\
\hline 2006 & 170 & $5(3.2)$ & $2(1.2)$ & $13(8.2)$ \\
\hline $2007 \ddagger$ & 117 & $2(2.1)$ & $1(0.9)$ & $9(8.1)$ \\
\hline $2008 \ddagger$ & 106 & $3(3.2)$ & $4(4.4)$ & $10(10.0)$ \\
\hline \multicolumn{5}{|c|}{$\begin{array}{l}\text { NOTE. Rates represent Kaplan-Meier estimates. } \\
* \text { Local recurrence (ipsilateral in-breast recurrence and new primary). } \\
+P<.05 \text { for trend in recurrence risk over time using linear regression analyses. } \\
\ddagger \text { Only } 43 \text { of } 92 \text { hospitals were included in the years } 2007 \text { and } 2008 \text {. }\end{array}$} \\
\hline
\end{tabular}

5-year LR rate in the unknown subtype group, mainly treated between 2003 and 2005, was 5.0\% compared with $2.6 \%$ when the biomarker subtype was known $(P=.039)$.

The risk of LR and RR varied with biomarker subtype. When the entire study period was considered, the differences between subtypes were borderline significant $(P=.056$ and $P=.014$ for LR and $R R$, respectively); however, when analyzed for the period after the introduction of trastuzumab (2005 to 2008), the observed differences leveled off $(P=.24$ and $P=.42$ for $L R$ and RR, respectively; Figs. $2 \mathrm{~A}$ and $2 \mathrm{~B}$ ). Patients with HR-negative/HER2positive tumors displayed the highest rate of LR (5.6\%), whereas patients with the TN subtype demonstrated the higher risk of RR (3.4\%). Patients with HR-positive breast cancer had a 1\% risk of LR, regardless of HER2 status, and similar low rates of RR were observed. In the 22 patients with HER2-positive status who were treated before 2005 and who did not receive trastuzumab, LRR was observed in four patients (18.2\%; 1 LR and $3 \mathrm{RR})$. In the 136 patients with HER2-positive statues who were treated from 2005 onward, including the administration of trastuzumab, locoregional events were observed in five patients (3.3\%; 3 LR and 2 RR).

The type of surgery did not influence the risk of LR. Overall, LR was 3.2\% after BCS versus 3.8\% after a mastectomy $(P=.617)$. Lymph node involvement at the time of surgery increased the risk of RR in the total population $(P=.035)$ as well as in all biomarker subtypes, albeit only significantly in the TN group $(P=.04)$.

\section{DISCUSSION}

In the present population-based cohort study of young patients with breast cancer, we observed a decreasing trend in the rates of LR and RR. This improved outcome concurred with increased knowledge of tumor biology (ie, different biomarker subtypes) combined with developments in systemic treatment, such as the introduction of trastuzumab, improvements in diagnostic imaging, and radiotherapy techniques and schedules. Both the LR and RR rates varied with biomarker subtype. Although low rates of recurrence were observed in HR-positive tumors, regardless of HER2 status, these rates were higher in TN and HR-negative/ HER2-positive tumors.
The overall 5-year rates of developing LR and RR were 3.5\% and $3.7 \%$, respectively. These rates showed a decreasing trend over time, and are lower than previously reported. In patients with stage I and II breast cancer age $<35$ years treated between 1989 and 1996, a study by Bartelink et $\mathrm{al}^{23}$ described a 5 -year cumulative incidence of LR of approximately $9 \%$ after radical excision, followed by 50 Gy radiotherapy with a boost. A decade later, a study by Van der Sangen et $\mathrm{al}^{10}$ reported a 5 -year LR rate of $4.4 \%$ after mastectomy versus $8.3 \%$ after breast-conserving therapy in patients age $\leq 40$ years with early-stage breast cancer who underwent surgery between 1988 and 2005. The data from the current study prove that the decreasing trend in the risk of locoregional breast cancer recurrence deducted from these previous studies continues, even when including higher stage disease.

Simultaneously, we observed a significant decrease in the occurrence of DM, also reported in previous studies, ${ }^{16,17}$ which is in line with reports that overall survival in patients with breast cancer has improved substantially in the last two decades. ${ }^{18,24}$

Throughout the study period, more than $90 \%$ of patients received chemotherapy and more than $95 \%$ hormonal treatment in case of HR-positive disease. The proportion of patients who received chemotherapy increased only slightly during the study period; therefore, an increasing proportion of patients receiving systemic treatment in itself is not a likely explanation for the reduction of locoregional and distant recurrences observed in the current study. Improvements in systemic therapy and the use of targeted drugs, such as trastuzumab, may have played an important role. This is supported by the fact that rates of LR and RR were lower in patients with a known biomarker subtype compared with patients with an unknown subtype who mainly received treatment in earlier years when HER2 testing and treatment with trastuzumab was not routinely applied. Earlier studies from Kiess et $\mathrm{al}^{25}$ and Lanning et $\mathrm{al}^{26}$ also observed lower rates of LRR in patients treated with trastuzumab.

Previous studies have stated that young age should be considered an independent risk factor for poor prognosis in patients with breast cancer ${ }^{27,28}$; however, the results of this study demonstrate that young age itself does not imply an increased 5-year rate of LRR. In patients with HR-positive breast cancer, the overall 5-year LR rate was comparable to LR rates previously reported for older patients, regardless of HER2 status. $^{29,30}$

Biomarker subtype was a prognostic factor for both LR and $\mathrm{RR}$, as has also been reported by others. ${ }^{31,32}$ The rate of LR was highest in patients with HR-negative/HER2-positive tumors followed by patients with TN tumors, whereas TN tumors displayed the highest $\mathrm{RR}$ rate. In the current study, the unfavorable HR-negative/HER2-positive and TN subtypes constituted approximately one half of all cases in the young age category after HER2 typing became common practice. In HRpositive breast cancer, the LR and RR risks were $<2 \%$, whereas in the HR-negative subtypes, these rates were higher. The fact that the differences between subtype-specific recurrence rates decrease when taking into account only patients that were treated after trastuzumab was reimbursed emphasizes that some improvement has already been accomplished. The range of LRR rates within the population of young patients with breast cancer proves that generalization of this young group regarding treatment choice would be incorrect. 


\section{A}

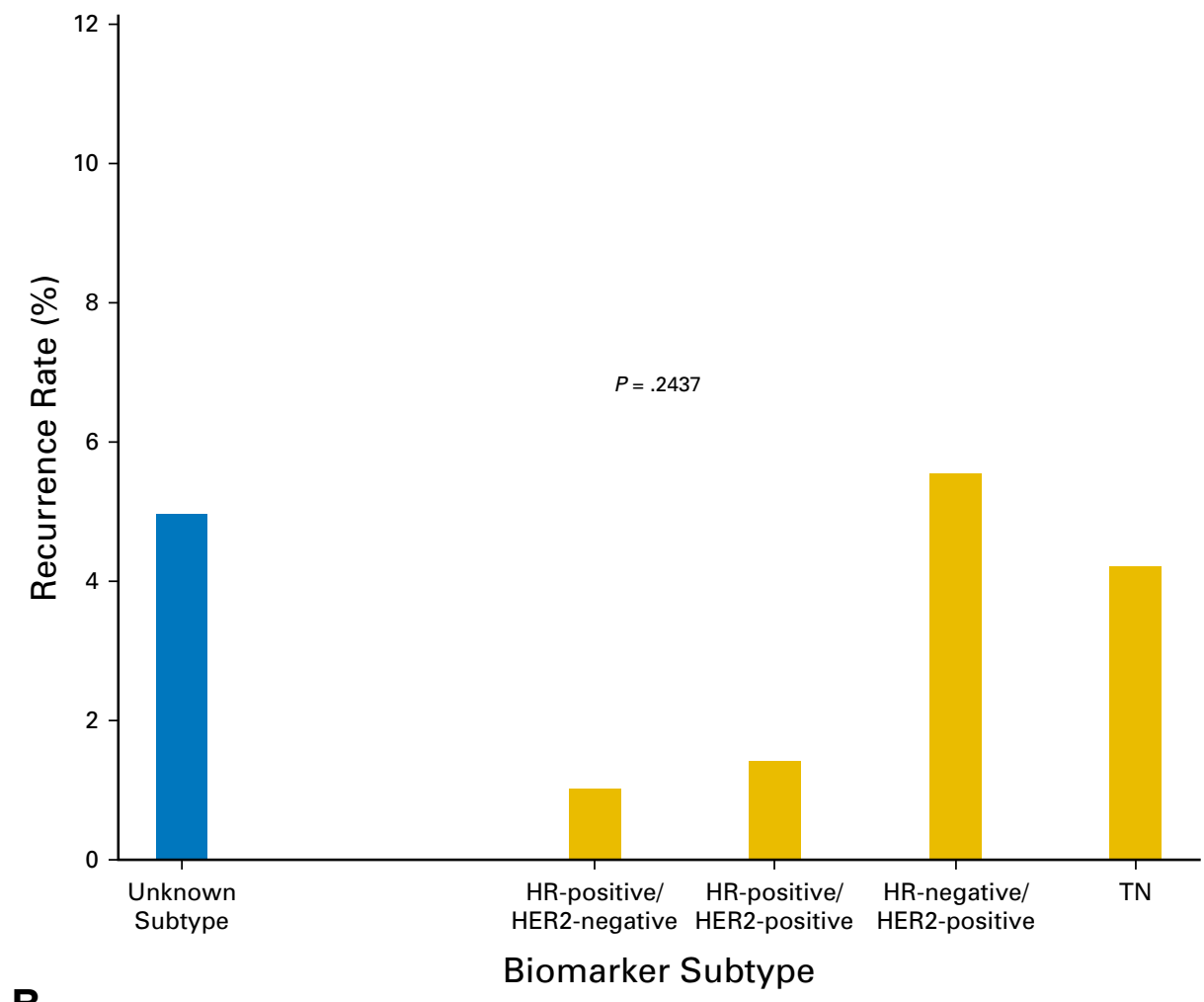

B

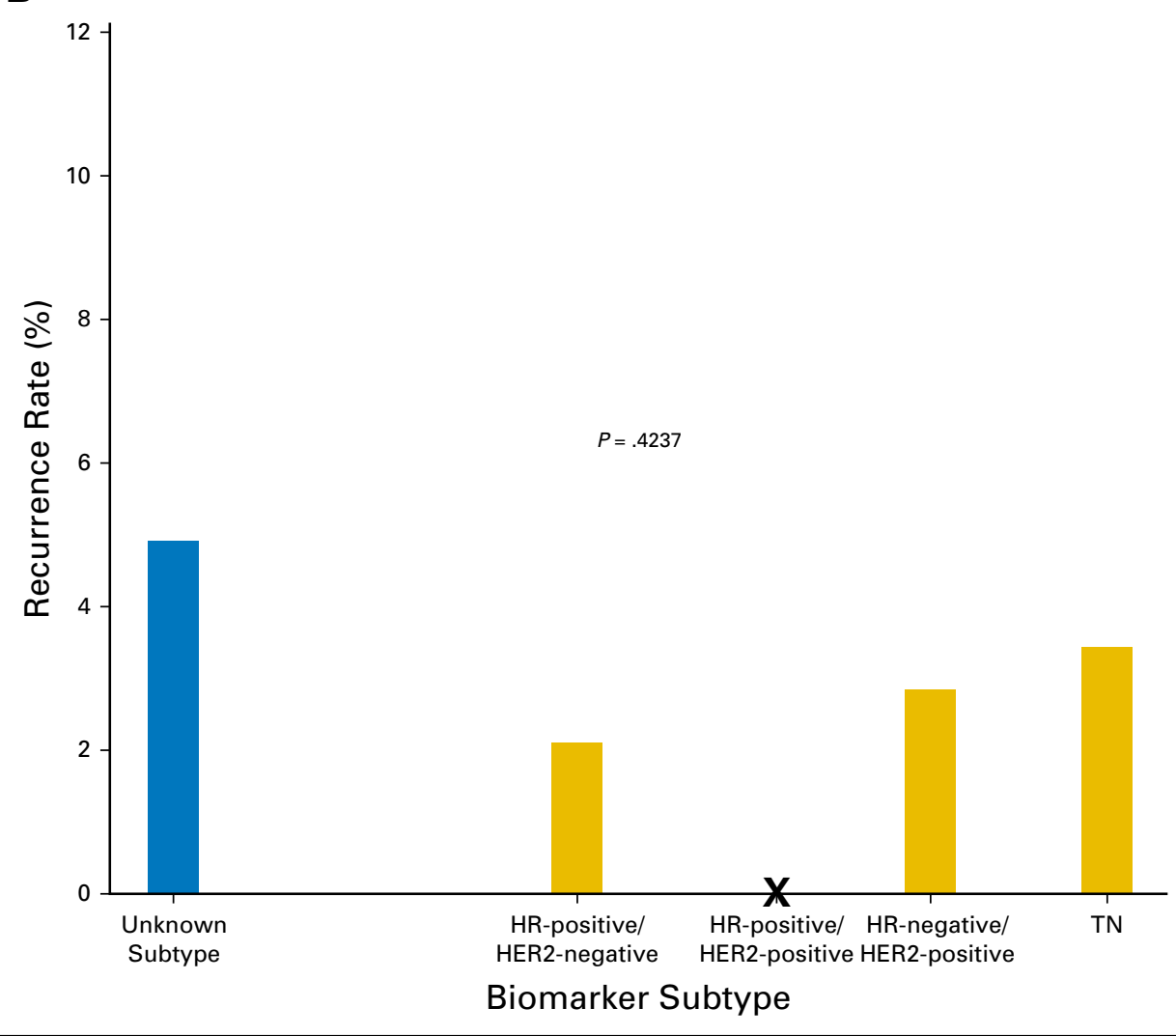

Fig 2. Five-year local recurrence (LR) and regional recurrence $(R R)$ rates in 1,000 young patients with breast cancer (age $<35$ years) surgically treated between 2003 and 2008 according to availability and kind of biomarker subtype on the basis of hormone receptor (HR) and human epidermal growth factor receptor 2 (HER2) status. The rates for the different biomarker subtypes are displayed for the period of 2005 to 2008 of patients treated with trastuzumab for HER2-positive disease. (A) LR according to availability and kind of biomarker subtype. (B) RR according to availability and kind of biomarker subtype. Thirty-five HER2positive patients who were treated before 2005 and/or who did not receive trastuzumab were excluded from analysis. Rates represent Kaplan-Meier estimates. $P$ values for differences between subtypes used log-rank tests. $\mathrm{TN}$, triple negative; $\mathrm{X}$, no patients had a RR. 
In the past, the high recurrence rates in young women have frequently led to the concept that mastectomy should be the preferred type of surgery in this patient population. ${ }^{14}$ Older studies on LRR, in times that HER2 status was not addressed, showed striking differences in the risk of developing LR after BCS versus mastectomy in young patients with breast cancer ${ }^{10}$ but with no influence on overall survival. ${ }^{33,34}$ In the current study, the type of surgery did not significantly affect risk of LR and RR; this was true for the entire cohort and the biomarker subtype subsets of patients.

A 5-year follow-up period is possibly too short to draw firm conclusions on the basis of the presented recurrence rates, especially in these young women with breast cancer. Although patients with breast cancer experience relapse most frequently in the first 5 years after primary treatment, HR-positive tumors, in particular, can have a longer time to recurrence. ${ }^{35-38}$ However, the LRR rates in this study were still substantially lower compared with previous reports. ${ }^{10,11}$ Longer follow-up is required to demonstrate whether the decreasing trend of the current study will extend to the 10-year and even 20-year recurrence rates.

The major strengths of this study are the population-based design and large study population with complete 5-year follow-up data, making the results generally applicable. Furthermore, data were registered in the NCR by trained personnel using a standardized coding manual. The definitions for LR and RR as used in this study are consistent with the definitions as established by consensus by Moossdorff et al. ${ }^{39}$

This study also has important limitations. Fewer patients were included from 2007 and 2008 because some hospitals did not provide follow-up data for those years. These patients' data consisted of a heterogeneous group in which exclusion on the basis of clinicopathologic and recurrence data in previous years should not have affected the representativeness of the nationwide breast cancer population for the period of 2007 and 2008. Although we aimed to include all stages of nonmetastatic breast cancer for analysis, the vast majority of patients (95\%) had early-stage breast cancer. Some selection resulted from the exclusion of patients treated with neoadjuvant chemotherapy as $50 \%$ of these patients had cT3 or cT4 tumors. The increased application of neoadjuvant treatment in smaller tumors could explain the observed proportional shift of tumor size over time. Data on biologic tumor factors, such as HR and, in particular, HER2 status, were limited before 2005 as they were not yet routinely assessed and central pathology review was not performed. In this study we stratified LRR rates according to biomarker subtype as defined by HR and HER2 expression. This classification, however, may not be as accurate as biomarker subtype classification on the basis of gene expression. In addition, information concerning specific radiotherapy and systemic therapy regimes, other than being administered or not, was not available. The administration of a boost dose could have played an important role in the reduction of LR. National guidelines at the time advised the routine administration of an additional radiotherapy boost to the primary tumor bed, and the Young Boost trial ${ }^{40}$ was conducted in the Netherlands during the study period comparing a standard 16-Gy boost with a 26-Gy boost.

As a result of the observational study design, there is the possibility of confounding by indication, which remains unsolvable even after using multivariable analysis as there will always remain the possibility of unknown or unmeasured risk factors. ${ }^{41,42}$ Because the number of recurrences was so low, multivariable analyses to correct for confounding and interaction were not feasible; results should be interpreted with this limitation in mind.

In conclusion, LRR rates in young patients with early-stage breast cancer decreased between 2003 and 2008, ending up relatively low. The higher recurrence rates in this young population were associated with the presence of more aggressive biomarker subtypes. Although longer follow-up is required, especially in these young women with breast cancer, the results of this study provide important insight into the LRR risks for this historically high-risk population.

\section{AUTHORS' DISCLOSURES OF POTENTIAL CONFLICTS OF INTEREST}

Disclosures provided by the authors are available with this article at www.jco.org.

\section{AUTHOR CONTRIBUTIONS}

Conception and design: Kim C. Aalders, Thijs van Dalen

Collection and assembly of data: Kim C. Aalders, Margriet van der Heiden-van der Loo

Data analysis and interpretation: All authors

Manuscript writing: All authors

Final approval of manuscript: All authors

\section{REFERENCES}

1. Nederlandse Kankerregistratie: Breast cancer incidence in the Netherlands [in Dutch]. http://www. cijfersoverkanker.nl

2. Elkhuizen $\mathrm{PH}$, van de Vijver MJ, Hermans J, et al: Local recurrence after breast-conserving therapy for invasive breast cancer: High incidence in young patients and association with poor survival. Int J Radiat Oncol Biol Phys 40:859-867, 1998

3. Gnerlich JL, Deshpande AD, Jeffe DB, et al: Elevated breast cancer mortality in women younger than age 40 years compared with older women is attributed to poorer survival in early-stage disease. J Am Coll Surg 208:341-347, 2009
4. Fredholm H, Eaker S, Frisell J, et al: Breast cancer in young women: Poor survival despite intensive treatment. PLoS One 4:e7695, 2009

5. Nixon AJ, Neuberg D, Hayes DF, et al: Relationship of patient age to pathologic features of the tumor and prognosis for patients with stage I or II breast cancer. J Clin Oncol 12:888-894, 1994

6. van de Vijver MJ, He YD, van't Veer LJ, et al: A gene-expression signature as a predictor of survival in breast cancer. N Engl J Med 347: 1999-2009, 2002

7. Anders CK, Hsu DS, Broadwater G, et al: Young age at diagnosis correlates with worse prognosis and defines a subset of breast cancers with shared patterns of gene expression. J Clin Oncol 26:3324-3330, 2008
8. Peto J, Collins N, Barfoot R, et al: Prevalence of BRCA1 and BRCA2 gene mutations in patients with early-onset breast cancer. J Natl Cancer Inst 91: 943-949, 1999

9. Malone KE, Daling JR, Neal C, et al: Frequency of BRCA1/BRCA2 mutations in a population-based sample of young breast carcinoma cases. Cancer 88 : 1393-1402, 2000

10. van der Sangen MJ, van de Wiel FM, Poortmans PM, et al: Are breast conservation and mastectomy equally effective in the treatment of young women with early breast cancer? Long-term results of a population-based cohort of 1,451 patients aged $\leq 40$ years. Breast Cancer Res Treat 127 : 207-215, 2011 
11. Voogd AC, Nielsen $M$, Peterse JL, et al: Differences in risk factors for local and distant recurrence after breast-conserving therapy or mastectomy for stage I and II breast cancer: Pooled results of two large European randomized trials. J Clin Oncol 19: 1688-1697, 2001

12. de Bock $G H$, van der Hage JA, Putter $H$, et al: Isolated loco-regional recurrence of breast cancer is more common in young patients and following breast conserving therapy: Long-term results of European Organisation for Research and Treatment of Cancer studies. Eur J Cancer 42:351-356, 2006

13. van der Hage JA, Putter $H$, Bonnema J, et al: Impact of locoregional treatment on the early-stage breast cancer patients: A retrospective analysis. Eur $J$ Cancer 39:2192-2199, 2003

14. van Nes JG, van de Velde CJ: The preferred treatment for young women with breast cancer: Mastectomy versus breast conservation. Breast 15: S3-S10, 2006 (suppl 2)

15. Nationaal Borstkanker Overleg Nederland: Richtlijn 'Behandeling van het mammacarcinoom' [in Dutch]. Alphen aan de Rijn, the Netherlands, Van Zuiden Communications BV, 2002

16. Geurts SM, Dijck J, Vegt Fd, et al: Huge decreases in the risk of breast cancer relapse over the last three decades. OA Epidemiology 19:1, 2013

17. Yerushalmi $R$, Woods $R$, Kennecke $H$, et al: Patterns of relapse in breast cancer: Changes over time. Breast Cancer Res Treat 120:753-759, 2010

18. Bouganim N, Tsvetkova $E$, Clemons $M$, et al: Evolution of sites of recurrence after early breast cancer over the last 20 years: Implications for patient care and future research. Breast Cancer Res Treat 139:603-606, 2013

19. de Munck L, Schaapveld M, Siesling S, et al: Implementation of trastuzumab in conjunction with adjuvant chemotherapy in the treatment of nonmetastatic breast cancer in the Netherlands. Breast Cancer Res Treat 129:229-233, 2011

20. Zorginstituut Nederland: 692 CVZ-advies: Vergoed herceptin ook bij niet-uitgezaaide Borstkanker [in Dutch]. Zorg en Financiering 5:89, 2006

21. Mukesh MB, Barnett GC, Wilkinson JS, et al: Randomized controlled trial of intensity-modulated radiotherapy for early breast cancer: 5-year results confirm superior overall cosmesis. J Clin Oncol 31: 4488-4495, 2013
22. Sobin LH, Wittekind $C$, (eds)Cancer UIUA: TNM Classification of Malignant Tumours (ed 6) Hoboken, NJ, John Wiley \& Sons, 2002

23. Bartelink $H$, Horiot JC, Poortmans PM, et al: Impact of a higher radiation dose on local control and survival in breast-conserving therapy of early breast cancer: 10-year results of the randomized boost versus no boost EORTC 22881-10882 trial. J Clin Oncol 25:3259-3265, 2007

24. Quaresma M, Coleman MP, Rachet B: 40-year trends in an index of survival for all cancers combined and survival adjusted for age and sex for each cance in England and Wales, 1971-2011: A populationbased study. Lancet 385:1206-1218, 2015

25. Kiess AP, McArthur $\mathrm{HL}$, Mahoney $\mathrm{K}$, et al: Adjuvant trastuzumab reduces locoregional recurrence in women who receive breast-conservation therapy for lymph node-negative, human epidermal growth factor receptor 2-positive breast cancer Cancer 118:1982-1988, 2012

26. Lanning RM, Morrow $M$, Riaz $N$, et al: The effect of adjuvant trastuzumab on locoregional recurrence of human epidermal growth factor receptor 2-positive breast cancer treated with mastectomy. Ann Surg Oncol 22:2517-2525, 2015

27. Azim HA Jr, Partridge $\mathrm{AH}$ : Biology of breast cancer in young women. Breast Cancer Res 16:427, 2014

28. Kroman $\mathrm{N}$, Jensen $\mathrm{MB}$, Wohlfahrt $J$, et al: Factors influencing the effect of age on prognosis in breast cancer: Population based study. BMJ 320 : 474-478, 2000

29. Botteri $E$, Bagnardi $V$, Rotmensz $N$, et al: Analysis of local and regional recurrences in breast cancer after conservative surgery. Ann Oncol 21 723-728, 2010

30. Van der Heiden-van der Loo $M$, Ho VKY Damhuis RAM, et al: Weinig lokaal recidieven na mammachirurgie: Goede kwaliteit van de Nederlandse borstkankerzorg [in Dutch]. Ned Tijdschr Geneeskd 154:A1984, 2010

31. Metzger-Filho $O$, Sun $Z$, Viale G, et al: Patterns of Recurrence and outcome according to breast cancer subtypes in lymph node-negative disease: Results from international breast cancer study group trials VIII and IX. J Clin Oncol 31:3083-3090, 2013

32. Nguyen PL, Taghian AG, Katz MS, et al: Breast cancer subtype approximated by estrogen receptor, progesterone receptor, and HER-2 is associated with local and distant recurrence after breast-conserving therapy. J Clin Oncol 26:2373-2378, 2008

33. Vila J, Gandini S, Gentilini O: Overall survival according to type of surgery in young $(\leq 40$ years) early breast cancer patients: A systematic meta-analysis comparing breast-conserving surgery versus mastectomy. Breast 24:175-181, 2015

34. Bantema-Joppe EJ, de Munck L, Visser O, et al: Early-stage young breast cancer patients: Impact of local treatment on survival. Int J Radiat Oncol Biol Phys 81:e553-e559, 2011

35. van der Ploeg IM, Nieweg OE, van Rijk MC et al: Axillary recurrence after a tumour-negative sentinel node biopsy in breast cancer patients: A systematic review and meta-analysis of the literature. Eur J Surg Oncol 34:1277-1284, 2008

36. Saphner T, Tormey DC, Gray R: Annual hazard rates of recurrence for breast cancer after primary therapy. J Clin Oncol 14:2738-2746, 1996

37. Fisher B, Jeong JH, Anderson S, et al: Twentyfive-year follow-up of a randomized trial comparing radical mastectomy, total mastectomy, and tota mastectomy followed by irradiation. $N$ Engl J Med 347:567-575, 2002

38. Clarke M, Collins R, Darby S, et al: Effects of radiotherapy and of differences in the extent of surgery for early breast cancer on local recurrence and 15-year survival: An overview of the randomised trials. Lancet 366:2087-2106, 2005

39. Moossdorff $M$, van Roozendaal LM Strobbe LJ, et al: Maastricht Delphi consensus on event definitions for classification of recurrence in breast cancer research. J Natl Cancer Inst 106: dju288, 2014

40. ClinicalTrials.gov: Radiation dose intensity study in breast cancer in young women. https:// clinicaltrials.gov/ct2/show/NCT00212121

41. Psaty BM, Koepsell TD, Lin D, et al: Assessment and control for confounding by indication in observational studies. J Am Geriatr Soc 47:749-754, 1999

42. Bosco JL, Silliman RA, Thwin SS, et al: A most stubborn bias: No adjustment method fully resolves confounding by indication in observational studies. J Clin Epidemiol 63:64-74, 2010

\section{GLOSSARY TERM}

biomarker: a functional biochemical or molecular indicator of a biologic or disease process that has predictive, diagnostic, and/or prognostic utility. 


\section{AUTHORS' DISCLOSURES OF POTENTIAL CONFLICTS OF INTEREST}

Contemporary Locoregional Recurrence Rates in Young Patients With Early-Stage Breast Cancer

The following represents disclosure information provided by authors of this manuscript. All relationships are considered compensated. Relationships are self-held unless noted. I = Immediate Family Member, Inst = My Institution. Relationships may not relate to the subject matter of this manuscript. For more information about ASCO's conflict of interest policy, please refer to www.asco.org/rwc or jco.ascopubs.org/site/ifc.

\section{Kim C. Aalders}

No relationship to disclose

\section{Emily L. Postma}

No relationship to disclose

Luc J. Strobbe

No relationship to disclose

Margriet van der Heiden-van der Loo

No relationship to disclose

Gabe S. Sonke

Research Funding: Roche (Inst), AstraZeneca (Inst), Novartis (Inst)

Travel, Accommodations, Expenses: Amgen, AstraZeneca, Novartis, Roche

\section{Liesbeth J. Boersma}

No relationship to disclose

Paul J. van Diest

No relationship to disclose

Sabine Siesling

No relationship to disclose

Thijs van Dalen

Research Funding: Agendia 
Appendix

\begin{tabular}{|c|c|c|c|c|c|c|c|}
\hline Characteristic & $\begin{array}{c}2003 \\
(n=213)\end{array}$ & $\begin{array}{c}2004 \\
(n=212)\end{array}$ & $\begin{array}{c}2005 \\
(n=182)\end{array}$ & $\begin{array}{c}2006 \\
(n=170)\end{array}$ & $\begin{array}{c}2007 \\
(\mathrm{n}=117)^{*}\end{array}$ & $\begin{array}{c}2008 \\
(n=106)^{*}\end{array}$ & $P$ \\
\hline \multicolumn{8}{|l|}{ Tumor histologic typet } \\
\hline Ductal & 193(91) & $193(91)$ & $157(86)$ & $155(91)$ & $104(89)$ & $95(90)$ & .278 \\
\hline Lobular & $8(4)$ & $6(3)$ & $5(3)$ & $2(1)$ & 3 (3) & $1(1)$ & \\
\hline Ductal + lobular & $4(2)$ & $1(0)$ & $11(6)$ & $4(2)$ & $4(3)$ & 3 (3) & \\
\hline Other & $8(4)$ & $12(6)$ & $9(5)$ & $9(5)$ & $6(5)$ & $7(7)$ & \\
\hline \multicolumn{8}{|l|}{ pT } \\
\hline $1 a$ & $2(1)$ & $8(4)$ & $9(5)$ & $8(5)$ & $3(3)$ & $6(6)$ & .004 \\
\hline $1 \mathrm{~b}$ & $14(7)$ & $16(8)$ & $20(11)$ & $16(9)$ & $11(9)$ & $10(9)$ & \\
\hline $1 \mathrm{c}$ & $60(28)$ & 75 (35) & $75(41)$ & $67(39)$ & $57(49)$ & $45(42)$ & \\
\hline 2 & $113(53)$ & $95(45)$ & $68(37)$ & $71(42)$ & $42(36)$ & $40(38)$ & \\
\hline 3 & $12(6)$ & $12(6)$ & $8(4)$ & $7(4)$ & $3(3)$ & $5(5)$ & \\
\hline 4 & $4(2)$ & $0(0)$ & $1(1)$ & $0(0)$ & $0(0)$ & $0(0)$ & \\
\hline$x$ & $8(4)$ & $6(3)$ & $1(1)$ & $1(1)$ & $1(1)$ & $0(0)$ & \\
\hline \multicolumn{8}{|l|}{$\mathrm{pN}$} \\
\hline pNO & $99(46)$ & $103(49)$ & $105(58)$ & $89(52)$ & $68(58)$ & $60(57)$ & .443 \\
\hline $\mathrm{pN} 1$ & 71 (33) & $74(35)$ & 47 (26) & $56(33)$ & $33(28)$ & $30(28)$ & \\
\hline $\mathrm{pN}>1$ & $42(20)$ & $33(16)$ & $30(16)$ & $25(15)$ & $16(14)$ & $16(15)$ & \\
\hline Unknown & $1(0)$ & $2(1)$ & $0(0)$ & $0(0)$ & $0(0)$ & $0(0)$ & \\
\hline \multicolumn{8}{|l|}{ Grade } \\
\hline Well differentiated & $10(5)$ & $10(5)$ & $11(6)$ & $12(7)$ & $8(7)$ & $4(4)$ & .564 \\
\hline Moderately differentiated & $51(24)$ & $48(23)$ & $54(30)$ & $37(22)$ & $36(31)$ & $26(25)$ & \\
\hline Poorly differentiated & $127(60)$ & $143(67)$ & $103(57)$ & $111(65)$ & $70(60)$ & $73(69)$ & \\
\hline Unknown & $25(12)$ & $11(5)$ & $14(8)$ & $10(6)$ & $3(3)$ & $3(3)$ & \\
\hline \multicolumn{8}{|l|}{ Multifocal } \\
\hline Yes & $14(7)$ & 30 (14) & $38(21)$ & 26(15) & $24(21)$ & $26(25)$ & .157 \\
\hline No & $99(46)$ & $122(58)$ & $135(74)$ & $141(83)$ & $91(78)$ & 79 (75) & \\
\hline Unknown & $100(47)$ & $60(28)$ & $9(5)$ & $3(2)$ & $2(2)$ & $1(1)$ & \\
\hline \multicolumn{8}{|l|}{ HR status } \\
\hline Positive & $76(36)$ & $91(43)$ & $110(60)$ & $92(54)$ & $61(52)$ & $59(56)$ & .776 \\
\hline Negative & $55(26)$ & $68(32)$ & $72(40)$ & $77(45)$ & $56(48)$ & $46(43)$ & \\
\hline Unknown & 82 (39) & $53(25)$ & - & $1(1)$ & - & $1(1)$ & \\
\hline \multicolumn{8}{|l|}{ Biomarker subtype } \\
\hline HR-positive/HER2-negative & $14(7)$ & $0(0)$ & 67 (37) & $61(36)$ & $45(38)$ & $43(41)$ & $<.001$ \\
\hline HR-positive/HER2-positive & $13(6)$ & $0(0)$ & $29(16)$ & $26(15)$ & $15(13)$ & $15(14)$ & $(2005-2008, .279)$ \\
\hline HR-negative/HER2-positive & $9(4)$ & $0(0)$ & $13(7)$ & $15(9)$ & $14(12)$ & $8(8)$ & \\
\hline TN & $8(4)$ & $2(1)$ & $56(31)$ & $57(34)$ & $41(35)$ & $38(36)$ & \\
\hline Unknown & $169(79)$ & $210(99)$ & $17(9)$ & $11(6)$ & $2(2)$ & $2(25)$ & \\
\hline
\end{tabular}

